\title{
Locating variation in the dative alternation ${ }^{1}$
}

\begin{abstract}
This paper explores the locus of variation in the dative alternation in dialects of Northwest British English.
\end{abstract}

Pronominal theme passives of apparent double object constructions (e.g. It was given her) are a well-known feature of Northwest English dialects. Detailed investigation reveals restrictions on the availability of theme passives vary systematically in different varieties, however. The paper focuses on Liverpool English, where theme passivisation is shown to derive from a prepositional dative with a null preposition; the availability of this 'prepositiondrop' is argued to be a product of morpho-syntactic innovation, rather than of PF-variability. Liverpool English is contrasted with Manchester English, where theme passivisation derives from double object constructions (Haddican 2010), argued to be available thanks to an extra functional head within the vP shell in double object constructions (Haddican and Holmberg 2012). Micro-variation in the morpho-syntax of adpositions vs. verbs correctly yields systematic differences in Northwest varieties, including (a) the class of the ditransitive verb that can participate in theme passives, (b) restrictions on the compatibility of certain goal arguments with theme passivisation, and (c) the type of theme argument that may undergo passivisation; these properties do not follow if variation is located in a post-syntactic domain.

\footnotetext{
${ }^{1}$ The research reported here was funded by the European Research Council Advanced Grant No. 269752 "Rethinking Comparative Syntax", and by Wolfson College, University of Oxford. I would very much like to thank my consultants for all their help, and especially Neil Myler and Becky Woods for judgements and for extremely useful discussion of the data. I am also very grateful to Theresa Biberauer, Bill Haddican, Anders Holmberg, Ian Roberts, Michelle Sheehan, and Sten Vikner for helpful comments and suggestions on various drafts of this paper, as well as the audiences of WCCFL 32 and the Cambridge Comparative Syntax of English Workshop for comments on the present version. I'd particularly like to thank two very insightful anonymous reviewers for Linguistic Variation. Any remaining errors are my own.
} 


\section{Introduction}

This paper examines the availability of Theme passives of ditransitive verbs in Northwest British dialects.
(1) a. It was sent him.
b. It was given her.

Previous dialectal studies on the Northwest have noted the availability of pronominal Theme passives, including for the Southwest Lancashire (Siewierska and Hollman 2007), Manchester (Haddican 2010, Haddican and Holmberg 2012), and Ormskirk (Myler 2011, 2013) varieties. Corpus-based research has also identified the structure as a feature of the region (Gerwin 2013, 2014).

In addition to pronominal Theme passives, new data shows that speakers of Liverpool English permit Theme passivisation of definite DPs:
(2) a. The book was given the teacher.
b. The package was sent her nan's.

To the best of my knowledge, (2) is not accepted in other varieties of English, ${ }^{2}$ including other Northwest varieties. ${ }^{3}$

\footnotetext{
${ }^{2}$ Crucially (2) involves definite NPs in surface subject position. It is well known that British English generally allows Theme passivisation of indefinite NPs (Woolford 1993, Ura 2000; McGinnis 1998, 2001; Anagnostopoulou 2003; Jeong 2007):

(i) A reward was offered the man. (Jespersen 1927: 279, cited in Woolford 1993: fn.8)

(ii) A watch was given him.
} 
This paper shows that a single surface string (i.e. (1)) can correspond to very different underlying syntactic structures in regional varieties.

I argue that Theme passivisation derives from a prepositional dative with a null preposition in the Liverpool variety. The availability of 'preposition-drop' is the result of a (possibly recent) morpho-syntactic innovation: a null Case-licensing element. I argue that this corresponds to the functional layer of prepositions, little $p$ (Svenonius 2007), but which does not establish a thematic relation to the Goal noun phrase, but does license it for (abstract) Case. This means that the structure of the null preposition is distinct from that of the overt preposition (whose pP embeds the lexical projection PP). The availability of the phonologically null functional item restricts the availability of dative constructions - and consequently passives of dative constructions - to a predictable class of environments.

In contrast, I argue that theme passives derive from short movement of the direct object in the double object construction in the rest of the Northwest (Haddican 2010), exemplified in this paper by a variety labelled Manchester English. Short movement is taken to be possible if some vP-internal head is available to value non-structural Case on $\mathrm{NP}_{\text {Goal }}$ (cf. Haddican and Holmberg 2012).

The two case studies support the hypothesis that the locus of variation is lexical (Borer 1984; Chomsky 1995; Adger and Smith 2010, i.a.), in the sense that apparent syntactic variation reflects variation in the distribution of morphosyntactic features on functional heads,

Speakers outside of the Northwest typically do not accept pronominal or definite Theme passives, however. The widespread availability of indefinite Theme passivisation suggests that it is distinct from the Theme passivisation found in the Northwest. As such I do not address its availability here.

${ }^{3}$ Speakers from Chester seem to accept the full DP in limited set of environments, for example with give ((2a) is judged possible, while (2b) is not), possibly under influence from the Liverpool variety. Chester is located on the border with Wales, around 20 miles south of Liverpool, and 40 miles southwest of Manchester. With thanks to Rebecca Woods for judgements and discussion. 
rather than variation in the types of syntactic operation available in the derivation, or variation in a post-syntactic component.

The data also constitute an example of parametric variation, where 'parameter' refers to a single morphosyntactic shift that results in a systematic and predictable array of phenomena through the rest of the grammar: the morphosyntactic analysis in this paper captures a range of syntactic restrictions on theme passivisation, which vary significantly but systematically across the region, including, (a) the status of the Theme that may undergo passivisation (pronoun vs. noun), (b) the class of the ditransitive verb that can participate in Theme passives, and (c) restrictions on the compatibility of different semantic Goal arguments with Theme passivisation. It is not possible to capture these restrictions if variation is located at PF.

The paper is laid out as follows. Section 2 discusses the scope and methodology of the paper. Those interested in the data and analysis can skip straight to Section 3, which shows that in Liverpool English, Theme passives derive from an underlying prepositional dative structure with a null preposition. Section 4 analyses the syntax of the null preposition. Section 5 contrasts Liverpool judgements with 'Manchester English' (as reported in Haddican 2010), and shows that the analysis of the dative alternation in Haddican and Holmberg (2012) correctly establishes a set of restrictions on the dative alternations in 'Manchester English' that are systematically distinct from those found in 'Liverpool English'. Section 6 discusses the consequences of the two analyses for theories of variation.

\section{Scope and methodology}

\subsection{Locating syntactic variation}


This paper investigates the variable availability of a set of constructions in varieties of Northwest British English. As in much work in generative syntax, here the (un)availability or (im)possibility of a syntactic structure is taken to be a distinct issue from variability in the use or production of that structure (although see Adger 2006, Adger and Smith 2010 for a reconciliation of the two issues).

The present paper reports on the results of a survey of groups of speakers of different regional backgrounds (discussed in detail in the next Section). Variability in the availability of a syntactic form amongst a specified class of speakers (rather than the individual) is usually referred to as microvariation. Recent notable investigations, and arguments for the import of identifying syntactic microvariation for generative and sociolinguistic study, include Cornips and Corrigan (2005), Adger (2006), Barbiers et al. (2008), and Zanuttini and Horn (2014). Of particular methodological significance for the present study is Kayne's (2005) observation that comparison of closely related linguistic varieties controls the set of possible grammatical variables, allowing for systematic and precise identification of varying features between groups of speakers.

The term 'microvariation' has often been used interchangeably with 'microparameter'. Parameter, here, is taken to be a point of variation in the grammar, with 'microparameter' contrasting with 'macroparameter' with respect to the number of effects traceable to that single point of variation. The data from the Northwest will demonstrate that a single variable can have significant repercussions to the syntax of a range of phenomena in otherwise closely related varieties. This highlights the need for distinguishing 'microvariation' in the sense of variation between closely related groups, and 'micro-parametric variation', as a single point of variation that may have implications for the rest of the grammar (cf. Baker 2008 for discussion of 'micro' changes with 'macro' effects, Biberauer, Roberts, and Sheehan 2014 for an explicit proposal on defining the 'size' of parameters). 
An important question regarding parameters is their locus in the architecture of the grammar. The familiar view in comparative syntax is that syntactic variation follows from variation in the inventory of syntactic features and their distribution across functional heads (in the spirit of Borer 1984), such that all variation is ultimately lexical variation. Alternatively it has been suggested that all variation is PF-variation (Berwick and Chomsky 2008); PF-variation might include the pronunciation or not of a given syntactic object. Discussion of Liverpool English focuses on the availability or not of preposition-drop, a plausible example of PF-variability. However I will argue that Liverpool preposition-drop is also best represented at the level of the functional lexicon. This 'lexical' variation (variation in the distribution of a set of features on functional heads) acts parametrically, in the sense that it yields a range of syntactic properties traceable to a single point of variation. The syntactic architecture itself (e.g. Merge, Probe-Goal Agree) does not vary.

\subsection{Methodology}

The data discussed in this paper are found in a variety of English that I label 'Liverpool English'. This is a post-hoc label adopted for expository purposes, for reasons set out in this Section.

The Liverpool English data are taken from a grammaticality judgement questionnaire, of the kind used in much formal, especially generative, syntactic investigations.

The generative method is adopted primarily because this paper addresses the question of the presence or absence of a particular form in a grammar, rather that form's usage or production (as discussed in the previous Section). The question of usage might be better addressed with a quantitative methodology. The rarity of the ditransitive structures in natural contexts in varieties of English mean that a corpus study is not pursued here; see Bresnan and Ford (2010), Siewierska and Hollman (2007), and Gerwin (2014) a.o. for discussion of the 
frequency of different types of ditransitive verb, and the forms those verbs typical take in corpora. A further problem for a corpus-based approach is the need to identify unacceptable or ungrammatical examples. Examples that are systematically judged acceptable by one group of speakers, and systematically rejected, by another set, are a crucial source of data here.

For the survey, speakers were told at the outset that their dialectal judgements were of interest, rather than their knowledge of prescriptive grammatical forms. Examples of forms from other dialects of English (I'm going t' pub) that were not expected to be part of the Northwest speakers' grammars were included in the survey to illustrate to consultants what might be considered a dialectal item, and to provide a control from which speakers could assess whether they would or would not accept or use a particular form.

The survey comprised constructed sentences. Questions were delivered simultaneously in verbal and written form. Consultants judged sentences as 'acceptable', 'marginally acceptable', 'marginally unacceptable', 'unacceptable', or 'don't know'; in the main text of this paper, marginality is indicated through use of a question mark or discussion of the relevant example. Consultants also had the option of ranking minimal pair examples relative to one another, and of providing their own comments on their intuitions. Each consultant was presented with roughly a third of the data reported in this paper; there was concern that use of the full set might induce judgement fatigue.

The Liverpool English results reflect the judgements of five male and four female speakers aged between 20-30. These consultants lived in the city of Liverpool (specifically, in one or more of the wards Toxteth, Allerton, Childwall, Wavertree, or Kensington) until at least the age of 18. Three of the informants have completed a Bachelor's degree in a University outside of Liverpool, three have obtained a Bachelor's degree from a university in Liverpool, and three left formal education at 16 . None have studied linguistics or have any 
linguistic-related training. Seven of the informants (from across the educational demographic) have lived outside Liverpool for at least three years. ${ }^{4}$

Only the regional background of the speaker seemed to be of significance. The dative alternation questionnaire was also delivered to a speaker from Southport (age 27) and to two Manchester English speakers (ages 25 and 29). These speakers gave systematically distinct judgements from the Liverpool speakers, corresponding instead with the judgements reported in Haddican (2010) for 'Northwest' speakers. ${ }^{5}$ I therefore label the judgements reported in Haddican (2010) and Haddican and Holmberg (2012) as 'Manchester English'. Haddican (2010) does not control for the precise regional background of participants (Haddican p.c.). ${ }^{6}$

Next, as will be discussed in Section 3, the same survey was delivered to speakers from Liverpool over the age of 60 . These speakers also gave distinct judgements from the first group of Liverpool speakers (they also patterned with the 'Manchester English' speakers).

Finally, the questionnaire was delivered to two 'Southern' (Oxfordshire and Bedfordshire) speakers as a control. These speakers gave different judgements from all of the Northwest English speakers, but consistent with the dative alternation judgements reported in

\footnotetext{
${ }^{4}$ This information is given to aid with the labelling of groups of speakers exhibiting systematically distinct grammars. Education, sex, and place of residence since the age of 18 did not appear to be relevant factors in whether a particular linguistic form was deemed acceptable or not, although it is possible these factors might affect the tendency to use or produce particular forms. The issue is not examined here, and of course the small size of the survey does not lend itself to meaningful exploration of this type of question.

${ }^{5}$ Southport is around 20 miles north of Liverpool, around 40 miles Northwest of Manchester, and around 8 miles Northwest of Ormskirk.

${ }^{6}$ Contrary to the broad findings of this paper, Haddican (2010: 2427) reports a low acceptability rate of full NP Theme-Goal Ditransitives for certain speakers. It is possible that these individual speakers share the grammar that I label 'Liverpool English'. The claim of this paper is not that certain linguistic forms will only occur in precise geographical regions; indeed this is empirically likely to be false, given that Gerwin's (2014: 152) corpus-based study identifies seven attestations of full noun Theme-Goal ditransitives right across England. Rather, the claim is that the availability of such a construction will be systematic, based on some morpho-syntactic innovation in a linguistic variety.
} 
the syntactic literature. This variety is labelled (for expository purposes only) 'Standard (British) English'.

The labels applied post-hoc to different groups are therefore adopted to highlight the systematic nature of the variation between the grammars of groups of speakers.

\section{Variation in the dative alternation}

\subsection{The dative alternation}

In English, ditransitive verbs can be realised in two ways. The first is via a Prepositional Dative, where $\mathrm{NP}_{\text {Theme }}$ precedes $\mathrm{NP}_{\text {Goal }}$ (or recipient, or source, etc.), with $\mathrm{NP}_{\text {Goal }}$ marked by a preposition (3a). The second is the double object construction (DOC), where $\mathrm{NP}_{\text {Theme }}$ follows $\mathrm{NP}_{\text {Goal }}\left(3 \mathrm{~b}\right.$ ), and $\mathrm{NP}_{\text {Goal }}$ is not marked by a preposition. This pair of constructions is known as the dative alternation.
(3) a. John gave the book to Mary.
THEME $>$ PP GOAL
Prepositional Dative
b. John gave Mary the book.
GOAL $>$ THEME
$D O C$

Following Larson (1988), there has been extensive discussion as to whether one construction is derived from the other (for example, the DOC from the Prepositional Dative). The dialect data presented here suggests that the two constructions are structurally distinct.

At least superficially, Northwest British English appears to permit local object movement: across the region the order Theme $>$ Goal in ditransitives is permitted (Hughes and Trudgill 1979; Gerwin 2013). I refer to the Theme $>$ Goal ordering as a Theme-Goal ditransitive, abbreviated to TGD, following Haddican (2010) and Haddican and Holmberg 
(2012). In a TGD the Theme precedes the Goal (as in a Prepositional Dative), but the Goal is not marked by a preposition (as in a DOC).
(4) a. John gave it to her.
Theme $>$ ppGoal
Prepositional Dative
b. John gave her it.
Goal $>$ Theme
$D O C$
c. John gave it her.
Theme $>$ Goal
Theme-Goal ditransitive

TGDs, like Theme passives, are known to be associated with Northwestern and Western varieties of England (Hughes and Trudgill 1979); TGDs are also associated with the Midlands (Gerwin 2013), the region immediately south of Liverpool and Manchester. The structure is also reportedly accepted by some speakers in Wales and from certain southern varieties, including London and Cornwall (Hughes and Trudgill 1979; Siewierska and Hollmann 2007; Haddican 2010: 2425; Haddican and Holmberg 2012; Gerwin 2013, 2014). There do not appear to be any reports of TGDs in Northeastern English or Scottish varieties. This geographic pattern has led to speculation that the availability of the Theme passive (5a) correlates with, and may be the result of, the availability of TGDs (5b) (Haddican 2010, Haddican and Holmberg 2012; see also Anagnostopoulou 2003).
(5) a. Mary gave it him.
Theme $>$ Goal
b It was given him (by Mary).
Theme passive

In this paper, another reason for believing there may be a correlation between the availability of TGDs and the availability of a Theme passive relates to a correlation in the type of noun phrases permitted in the two structures. The following examples show that Manchester English speakers only permit pronominals in TGDs, and only permit pronominals 
as the derived subject of Theme passives. They do not permit full NP Themes in either TGDs, or in Theme passives.

(6) a. Mary gave it the teacher.

( ${ }^{\mathrm{OK}}$ Liverpool, ${ }^{\mathrm{OK}}$ Manchester)

b. It was given the teacher.

( ${ }^{\mathrm{OK}}$ Liverpool, ${ }^{\mathrm{OK}}$ Manchester)

Liverpool speakers accept the pronominal structures in (6), but also accept NP Themes in both TGDs and in Theme passives.

(7) a. Mary gave the book the teacher.

b. The book was given the teacher.

(8) a. Mary sent the package her nan's.

b. The package was sent her nan's.
( ${ }^{\mathrm{OK}}$ Liverpool, *Manchester)

( ${ }^{\mathrm{OK}}$ Liverpool, *Manchester)

( ${ }^{\mathrm{OK}}$ Liverpool, *Manchester)

( ${ }^{\mathrm{OK}}$ Liverpool, *Manchester)

The correlation between the two constructions and pronominal sensitivity further suggest that the Theme passive construction may be related to the availability of TGDs.

Haddican (2010) and Haddican and Holmberg (2012) discuss this correlation as a possible one-way implication, where the availability of Theme passives is reliant on the possibility of TGDs in the same dialect:

(9) The availability of Theme passivisation correlates with the availability of TGDs.

(Haddican 2010, Haddican and Holmberg 2012: 199) 
Following (e.g.) McGinnis (1998, 2001), the theme passive might then taken to be a product of the availability of short direct object movement, as a reflex of (e.g.) an EPP feature on the vP-internal projection introducing the indirect object. This 'pure locality' approach predicts that the availability of short object movement and Theme passivisation should be a bi-conditional, such that wherever TGDs are available, Theme passivisation should also be possible. However, there are many British dialects that permit TGDs that do not exhibit Theme passivisation (Haddican and Holmberg 2012; Gerwin (2013) on the Midlands). This suggests that the correlation between Theme passivisation and TGDs may be uni-conditional. We will see that Case and agreement features, with distinct distributions across the functional structure of different dialects, must play a role (cf. Haddican and Holmberg (2012).

\subsection{Variation in Theme passives and TGDs in Liverpool English}

This Section presents evidence that Liverpool English TGDs do not derive via local direct object $\left(\mathrm{NP}_{\text {Theme }}\right)$ movement in a DOC, but instead derive from the Prepositional Dative.

Building on Haddican (2010) we can establish the underlying structure of the TGD using the well-known observation that usage of the dative alternation in English is not arbitrary, but is constrained by factors such as the semantics of the ditransitive verb (Green 1974, Oehrle 1976; cf. also Haddican 2010). The traditional distinction between the two constructions is that the DOC implicates transfer of possession, while the Prepositional Dative encodes transfer of location, but not necessarily possession. The generalisation can be illustrated through negation (Pesetsky 1995, Harley 2002):

(10) a. James taught the students Japanese, ?? but they didn't learn anything.

b. James taught Japanese to the students, 'but they didn't learn anything. 
The argument goes that it is not felicitous to negate possession in (10a), as DOCs necessarily imply transfer of possession (here, knowledge of Japanese). In contrast, a Prepositional Dative does not necessarily imply transfer of possession, so it is possible to negate a possession relation (10b). Leaving aside the adequacy (and analysis) of this generalisation, the intuition captures the observation that speakers systematically use the Prepositional Dative ditransitive structure to convey allative semantics, and the DOC to express possessive semantics. The distinction holds across a range of verb classes and therefore provides a diagnostic to determine the underlying structure of TGDs (as in Haddican (2010)), and consequently the structure underlying the availability of theme passivisation.

First, 'verbs of continuous imparting of force' (carry, pull, push, lift, lower, haul) are fully acceptable as Prepositional Datives, but are degraded in DOCs (Pinker 1989, Levin 1993; Bresnan and Nikitina 2009). This contrast is consistent with Liverpool speakers' judgments. Therefore if Liverpool TGDs are Prepositional Datives, Liverpool speakers should allow TGDs with verbs of continuous imparting of force. This prediction is borne out:

(11) a. She hauled her shopping to the front door.

PD

b. *She hauled the front door her shopping. ${ }^{7}$

DOC

\footnotetext{
${ }^{7}$ Some speakers (of both Liverpool and non-Liverpool British English) report the DOC examples in (11b) and (12b) as acceptable, in contrast to the judgments described in the main text. However, acceptability seems to be linked to a benefactive interpretation, 'on behalf of'. Crucially this is not the reading associated with the TGD, and for this reason I exclude this judgement.

There are signs that the status of such 'benefactives' could provide rich ground for future investigation in variation in British dialect syntax. For example, Liverpool speakers permit passivisation of certain benefactive classes of ditransitives: 'The toy was bought the child' was accepted by all consultants (Haddican 2010 reports this structure is not accepted by Manchester English speakers). An anonymous reviewer points out that some Northwestern dialect speakers permit Theme-beneficiary orders such as 'She baked/bought it me'. This structure is also available in Liverpool English, as are full DP Theme-beneficiary: 'I bought
} 
(12) a. She pushed/hauled/lifted it to me.

PD

b. *She pushed/hauled/lifted me it.

DOC

c. She pushed/hauled/lifted it me.

TGD

(Liverpool)

'Manner of communication' verbs (whisper, yell, bark, grumble, mutter) also typically occur as Prepositional Datives, and are reported as degraded in DOCs (Bresnan and Nikitina 2009: 165). Again, this verb class is compatible with TGD in Liverpool British English, but not in DOCs, supporting an analysis of Liverpool TGD as underlying Prepositional Datives.

(13) a. She muttered the answer to my friend.

PD

b. *She muttered my friend the answer.

DOC

c. She muttered the answer my friend.

TGD

(14) a. She whispered/shouted it to me.

PD

b. *She whispered/shouted me it.

DOC

c. She whispered/shouted it me.

TGD

(Liverpool)

the toy the child' (similar to the examples in $11 \mathrm{~b}, 12 \mathrm{~b}$ ). Other examples such as "I made the cake (for) Bill', were possible for some speakers, but only where the Goal (Bill) was interpreted as possessing the cake. True benefactives of intransitives (*'I danced Mary') were deemed outright ungrammatical.

These structures were not tested systematically in the present study, and from this limited data it is not clear that the (null preposition/null $\kappa$ ) analysis pursued for prepositional datives (introduced in detail in Section 4) should be extended to this class. I leave full investigation and analysis to future research. 
Finally, 'latinate' ${ }^{8}$ verbs (contribute, distribute, exhibit, reveal, conceal, clarify, compose, release) are also typically judged better in Prepositional Dative structures than in DOCs. Once again, as predicted, TGDs pattern with Prepositional Datives among Liverpool English speakers.

(15) a. She donated her loose change to the Alder Hey fund. PD

b. * She donated the Alder Hey fund her loose change. DOC

c. She donated her loose change the Alder Hey fund. TGD

(16) a. She donated it to him.

PD

b. *She donated it him.

DOC

c. She donated it her.

TGD

d. She donated it it.

TGD

(Liverpool)

Crucially, speakers of Liverpool English reject TGDs with verbs that are incompatible with the Prepositional Dative construction. For example, 'prevention of possession verbs' (refuse, cost, deny) as well as verbs including issue, ask, and envy, are canonically accepted in DOCs but degraded in Prepositional Dative structures (Levin 1993; Bresnan and Nikitina 2009:167). As predicted, Liverpool speakers do not accept these verb classes in TGDs. The data strongly suggest that Liverpool speakers treat TGDs as Prepositional Datives.

\footnotetext{
8 'Latinate' is an insufficient etymological characterization of the class, as many verbs (such as refuse: REFUTARE or deny: *DE+NEGARE) are of latinate origin (Adam Ledgeway, p.c.), but, as discussed in the text, exhibit a distinct behaviour. I adopt 'latinate' for consistency with previous literature.
} 
(17) a. *The car cost five grand to Beth.

PD

b. The car cost Beth five grand. DOC

c. *The car cost five grand Beth. TGD

(18) a. *She denied the ice cream to the child. PD

b. She denied the child the ice cream. DOC

c. * She denied the ice cream the child. TGD

(19) a. *She envied the ice cream to the child. PD

b. She envied the child the ice cream. DOC

c. * She envied the ice cream the child. TGD

(20) a. *She refused it to me. PD

b. She refused me it. $\quad$ DOC

c. * She refused it me. TGD

(Liverpool)

These data are unexpected if the Liverpool TGD derive from a DOC. (A short object movement in a DOC is also unexpected given that Liverpool TGDs are not restricted to pronominal themes, unlike in neighbouring varieties (Section 3.1)), but unsurprising if Liverpool TGDs are Prepositional Datives.

Having established that such a structure is available in Liverpool English, it is plausible to conclude that the theme passive is simply a theme passive of a Prepositional Dative that lacks an overt preposition. 
(21) a. It was given $\left[\right.$ to $\left._{\text {NULL }}\right]$ her.

b. I gave it $\left[\right.$ to $\left._{\mathrm{NULL}}\right]$ her.
Theme passive

TGD/ Prepositional Dative

(Liverpool)

If Theme passives derive from TGDs, and TGDs themselves are Prepositional Datives, theme passives should only be available with those verb classes canonically associated with Prepositional Datives. This prediction appears to be true: in the Liverpool variety, Theme passivisation is possible with manner of communication verbs, verbs of continuous imparting force, and latinate verbs, but not with verbs of prevention of possession.

(22) a. Her shopping was hauled the front door by a kindly neighbour.

b. The code was whispered Mary before Sally knew what was happening.

c. The answer was muttered my friend, who passed it on to me.

d. The winnings from last week's draw were donated Alder Hey Hospital.

(23) a. It was whispered her before she knew what was happening.

b. It was donated the hospital last week.

(24) a. *Five grand was cost the car.

b. *The ice cream was denied the child.

c. *The ice cream was envied the child.

d. *It was refused her.

(Liverpool) 
When compared to 'standard' varieties of English, the Liverpool variety is thus 'wellbehaved' with respect to the availability of passives of ditransitives: it simply includes an additional element $\left[\right.$ to $\left._{\mathrm{NULL}}\right]$. The crucial point to be established in the next Section, then, is that $\left[t o_{\mathrm{NULL}}\right]$ has the capacity to license the Goal in both active and passive contexts. ${ }^{9}$

\section{Preposition-drop}

\subsection{The syntax of preposition-drop}

The availability of $\left[t_{\mathrm{NULL}}\right]$ appears to derive from the recent increase in the availability of preposition-drop in the dialect, of the following kind:

(25) a. I want to go Chessington.

b. John came the pub with me.

(Haddican and Holmberg 2012:74; Myler 2013: 189)

Preposition-drop has been reported in a number of varieties of Northwest British English, including Manchester (Haddican 2010), and especially South-West Lancashire and Merseyside (Myler 2011, 2013): in all these varieties, it is possible to leave the preposition to null. As Myler (2013) observes, the realisation of the preposition in these contexts is optional: the use or non-use of the overt preposition triggers no difference in thematic or truth-

\footnotetext{
${ }^{9}$ Further diagnostics distinguishing prepositional datives from the DOC include animacy and idiom-based tests. As the results of the grammaticality judgement tests (although consistent with the conclusions drawn here) were less clear than for those diagnostics reported in the main text, I do not discuss them. I could not find any evidence of a PCC effect amongst the Liverpool English speakers. This result is again consistent with the prepositional dative analysis, but as this is a notoriously subtle judgement I leave discussion to one side.
} 
conditional meaning, and speakers appear to be unconscious of the use or non-use of the overt form in discourse. Nonetheless its availability is highly systematic. For example, Myler $(2011,2013)$ observes that Ormskirk p-drop is restricted to a narrow class of verbs: verbs of motion (whose Goals can only be interpreted as directional) such as go, run, drive, jog, pop, and nip ('to go somewhere with the intention of returning quickly'); and the ditransitives take and send (Myler 2013:190).

The Liverpool variety permits far more extensive preposition-drop than these neighbouring varieties. ${ }^{10}$ First, Liverpool speakers accept preposition-drop in a range of allative to contexts, such as non-allative and manner-of-motion contexts:

(26) a. Swim the end and back.

$=$ 'Swim to the end and back.'

b. She ambled the shop.

$=$ 'She ambled to the shop.'

c. He’s flying Germany tomorrow.

$=$ 'He's flying to Germany tomorrow.'

d. The USSR was the first to fly the moon. = '...to fly to the moon.'

e. He meandered his way the office. = ' = He meandered his way to the office.'

f. Joe plodded the pub. = 'Joe plodded to the pub.'

In addition, and again in contrast to the Ormskirk variety (Myler p.c.), Liverpool speakers can leave stative at phonetically unrealised. This is possible with (at least) stative predicates, the copula, and unaccusative predicates. I re-label $\left[t_{\mathrm{NULL}}\right]$ as ' $\kappa$ ' as a neutral label to cover its distribution with both the directional and the stative marker; all instances of $\kappa$ are null.

(27) a. She's staying John's tonight.

$=$ 'She's staying at John's tonight.'

\footnotetext{
${ }^{10}$ Ormskirk is around 13 miles north of Liverpool.
} 

b. I'm working the library today.
$=$ 'I'm working at the library.'
c. He's his dad's this weekend.
$=$ 'He's at his dad's house this weekend.'
d. She'll be the office late tonight.
$=$ 'She'll be at the office late tonight.'
e. He just arrived the gym.
$=$ 'He just arrived at the gym.'

The availability of at-drop is the first clue that Liverpool null prepositions are significantly different from preposition-drop in the rest of the Northwest: (26) and (27) are ungrammatical in the Ormskirk variety (Myler p.c.), and as preliminary investigation suggests preposition-drop in the rest of the Northwest region corresponds to the system Myler (2013) identifies for Ormskirk, I tentatively conclude that (26) and (27) are restricted to Liverpool English.

The distribution of $\kappa$ is not completely free in Liverpool English, however: only to and at may be null; the source preposition from, containment in, and apparently all other prepositions must be overt.

(28) a. He started *(from) the station. (source)

b. This cheese comes *(from) Lanarkshire. (provenance, origin)

c. He put the beers *(in) the fridge. (containment)

d. The plane will shortly be $*^{/ ?}$ (in) the air. (surrounding)

e. Can you finish *(in) three hours? (duration)

f. She's *(in) a coma. (state)

g. She went *(with) her friends. (alongside)

h. The bread was cut*(with) a knife. (by means of) 
i. She'd lived ${ }^{? ? / *}$ (on) that street her whole life. ${ }^{11}$

j. I haven't got any money*(on) me.

k. He left everything *(on) the table for you.

(Liverpool)

The prepositions that may be dropped in Liverpool English - to and at - thus fit the typology proposed in Caponigro and Pearl (2008: fn.383), who suggest, 'across languages, only the unmarked stative and directional Ps at and to, not the marked source directional preposition from, can fail to be pronounced. ${ }^{, 12}$

This restricted distribution offers a first diagnostic to relate the availability of $\kappa$ to the availability of Theme passivisation in Liverpool English. If Liverpool English TGDs and Theme passives are Prepositional Datives with null $\kappa$, they should not be available with prepositions other than to and at. This prediction is borne out:

(29) a. Beth put the beers *(in) the cooler.

b. The beers were put*(in) the cooler.

\footnotetext{
${ }^{11}$ This example is more acceptable relative to the rest, but appears to be also available in varieties outside of the Northwest. For example, in the British English Bedfordshire variety, 'How long have you lived Bedford?' Michelle Sheehan (p.c.) is fully acceptable. An anonymous reviewer points out that Wolfram and Schilling-Estes (2006: 69) similarly observe that missing in is possible in some varieties of American English, as in 'She lives $\varnothing$ Coal City'.

${ }^{12}$ An outstanding issue for the present analysis, as well as other work on preposition-drop, is why such a null preposition cannot be interpreted freely, for example as null SOURCE; see fn. 24, and Gehrke and Lekakou 2013, for further discussion. For now I simply note that many languages in which preposition-drop is found exhibit a morphologically syncretic form for to and at (such as Greek se 'to, at'), and that preposition-drop always seems to require this interpretation. The restriction is robust: for example Standard English home requires an overt source preposition, as in He came *(from) home (cf. Collins 2007 discusses home in detail).
} 
(30) a. Beth exchanged notes *(with) Pete.

b. Notes were exchanged $*($ with) Pete.

(Liverpool)

Evidence from language change also supports a connection between $\kappa$ and the availability of theme passivisation in the dialect. The judgements reported so far are taken from a survey of nine native speakers of Liverpool English aged between 20-30 (cf. Section 2.2). The same survey was extended to six native speakers of Liverpool English over the age of 60. In contrast to the younger speakers, the older speakers restrict TGDs to pronominal themes, the pattern in the rest of the Northwest. Crucially, the older speakers also reject generalised preposition-drop (or rather, $\kappa$ ), and again report the system of preposition-drop that seems to be available in the rest of the Northwest (the system described in Myler 2013). This suggests a correlative (and plausibly causative) relation between speakers' innovation of $\kappa$, and the availability of full noun phrase theme passivisation.

\subsection{The syntax of $\kappa: \kappa$ Case licenses Goals}

The next step is to determine the role of $\kappa$ in the grammar. Initial evidence that $\kappa$ is a lexical item, present in the syntax, is the availability of straight-modification, a classic diagnostic of prepositions (Emonds 1985). ${ }^{13}$ Liverpool speakers accept straight-modification without the overt preposition, suggesting that, despite the absence of overt material, the syntax treats the Goal as if it is marked by a preposition:

\footnotetext{
${ }^{13}$ Consultants generally wouldn't accept p-drop examples with right-modification, the other classic modification diagnostic of $\mathrm{P}$. This may be a register problem: it was also difficult to get speakers to accept right-modification examples with the overt preposition.
} 
(31) a. I'm going straight the pub after this. = 'I'm going straight to the pub after this.'

b. He's heading straight the office. = 'He's heading straight to the office.' 14

This is consistent with much past work, which has shown that, although p-drop may appear to be an example of PF-variability, its distribution is best defined syntactically (Collins 2007; Ioannidou and den Dikken 2009; Terzi 2010; Gehrke and Lekakou 2013; Myler 2013).

Past accounts of p-drop vary, but most take as their starting point den Dikken's (1995, 2010) suggestion that an inherently null functional head must incorporate (to the verb) to be licensed as null, and thus that 'PF-variability' is sensitive syntactic environment. ${ }^{15}$ This Section shows that Liverpool p-drop does not involve incorporation. This will prove crucial: it is variation in the adpositional lexicon that means that theme passivisation of the kind found in Liverpool English is not found in the rest of the Northwest. The regional variation is laid out through comparison of Liverpool English with Myler's (2013) account of Ormskirk English, already discussed in Section 4.1.

Myler (2013) shows that in Ormskirk English, preposition-drop appears to be restricted syntactically, to the environment of incorporation. ${ }^{16}$ Myler proposes that in Ormskirk English, in a structure like John came the pub, the Goal argument (which exhibits properties of both

\footnotetext{
${ }^{14} \mathrm{An}$ anonymous reviewer suggests that the availability of straight-modification is problematic if (anticipating Section 4.3) $\kappa$ bears only $\mathrm{u}[\mathrm{F}]$, as apparently similar athematic case markers assumed to bear only $\mathrm{u}[\mathrm{F}]$, such as of (*The destruction straight of the city) or by (*The book was written straight by John), do not permit straight-modification. I assume that straight-modification is category sensitive, restricted to modification of spatial $p / \mathrm{P}$. It can therefore modify $\kappa$ (category $p$ ) but not of (D) or by (Voice) (cf. Collins 2005) or for (Comp). Similarly, $\kappa$ cannot substitute for by or of or for elsewhere because it is not of an appropriate category.

${ }^{15}$ P-incorporation seems to be the most widespread strategy licensing p-drop crosslinguistically, as has been discussed for Greek dialects (Ioannidou and den Dikken 2009; Terzi 2010; Gehrke and Lekakou 2013), Veneto dialects (Longobardi 2001:289), and Gungbe (Aboh 2010: 229).

${ }^{16}$ The same conclusion has been drawn for preposition-drop in Greek dialects (Ioannidou and den Dikken 2009; Terzi 2010; Gehrke and Lekakou 2013).
} 
direct objects and PP objects) is the complement of a directional preposition (silent) TO, and that, following (den Dikken 1995, 2010), an inherently null functional head must incorporate (to the verb) to be licensed as null.

Myler argues that this incorporation is available precisely in the context of unaccusativity. On standard assumptions, transitive $v$ inherits $\varphi$ from the phase head Voice

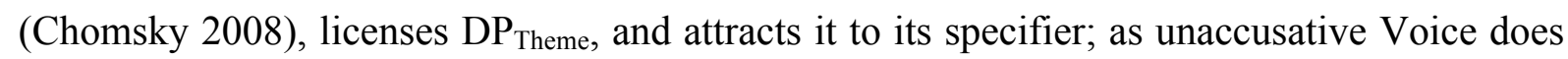
not bear $\varphi$ to 'pass down' to $v$, unaccusative $v$ does not license $\mathrm{DP}_{\text {Theme }}{ }^{17}$ Following Svenonius (2007) (a.o.), adpositions bear $\varphi$-features, which license the Goal argument. Myler (2013) argues that in Ormskirk English, the requirement of directional TO to incorporate (to license its inherent null-ness) gives rise to (P-to-)p-to-v ${ }^{18}$ movement in the environment of unaccusative $v$, such that TO ends up in the same complex head as $v$. Through this movement, $v$ 'inherits' the $\varphi$-features of $p$, and the apparently unaccusative $v$ can $\varphi$-license the Goal. As $v$ $\varphi$-license the Goal, the Goal necessarily raises to spec- $\nu$ P. 'Preposition-drop' is thus a product of an inherently null lexical item that is licensed in a strictly defined set of syntactic conditions.

Myler's account (more nuanced details of which are omitted here for reasons of space) yields a rich array of empirical facts of preposition-drop in Ormskirk English. Crucially, though, these properties are not found for Liverpool English preposition-drop. Two points are sufficient to make the distinction clear.

\footnotetext{
${ }^{17}$ Myler assumes that Voice, which introduces external arguments, is a distinct functional layer to the verbalizing head $v$, which is the categorizer of the root (Marantz 1997).

${ }^{18}$ Myler's (2013) null preposition is taken to have the 'split' structure of overt prepositions, where a lexical head $\mathrm{P}$ responsible for selecting a complement is contained by a functional layer $p$, with $p$ responsible for $\varphi$-licensing the complement of $\mathrm{P}$ (and for introducing the external argument of the adposition) (cf. Svenonius 2003, 2007, 2010 for extended justification of this structure for adpositions).
} 
First, Myler $(2011,2013)$ observes that Ormskirk p-drop is sensitive to a restricted class of verbs; it is this limited class of verbs that permits p-incorporation. The last Section showed that Liverpool p-drop does not exhibit such sensitivity.

A second consequence of the incorporation account is that in Ormskirk English, p-drop is licit only where the Goal is adjacent to the verb. ${ }^{19}$ In contrast, as shown in detail below, the Liverpool variety permits preposition-drop in contexts in which the verb and Goal are nonadjacent.

First, in Liverpool English the unmarked Goal can be embedded in a nominal domain, non-adjacent to the verb:

(32) a. An errand the shops is called for.

b. He was on his way the library when...

c. A trip the pub is called for!

(Based on Myler 2013: 198)

Next, in Liverpool English, an additional prepositional phrase may intervene between the verb and the Goal, such that the Goal is non-adjacent to the verb (33). (34) gives examples of ditransitives, where $\mathrm{NP}_{\text {Theme }}$ intervenes between the verb and the Goal.

(33) a. Come with me (to) the pub.

b. He took them both (to) the zoo.

(34) a. I took Joey the hospital

\footnotetext{
${ }^{19}$ Crucially for Myler (2013), 'adjacency' means that the Goal has moved to a position canonically associated with the direct object, rather than linear adjacency. For ease of exposition I simply refer to adjacency here; the key point is that Liverpool English permits pdrop where a nominal is non-adjacent (either linearly or syntactically) to the verb.
} 
b. He sent the package (back) his nan.

The Goal is possible not only in positions non-adjacent to the verb, but can undergo discourse-shift independently of the verb. (35) shows Liverpool speakers can topicalise the unmarked Goal, and (36) shows that the Goal is compatible with it-clefts.

(35) She said we'd go the pub, and the pub we went.

(36) a. It's the shops we're going, not the pub!

b. She said it's Chester they're moving

c. It's the office he'll be working today

The availability of clefting, and in particular, the interpretation of clefts, has consequences elsewhere. In (37a), non-Liverpool English speakers report an ambiguity between a directional and a locational reading, but once clefted (37b), only the locational reading is available.

(37) a. Suarez ran on the pitch.

b. It was on the pitch that Suarez ran.

(Based on Stringer 2006: 64, cited in Cinque 2010: fn.12)

I take this ambiguity to follow from the semantic and structural complexity of the adposition in question, here, on. It is widely assumed that the internal structure of PPs is complex relative to its conceptual complexity (Jackendoff 1983, Svenonius 2010 i.a.). The internal structure may or may not be overtly realised. For example, it has been argued widely 
that a projection PathP (realised by e.g. to) always contains (embeds) a lexical projection PlaceP (realised by e.g. at) (Jackendoff 1983, Koopman 2000 i.a.), although that embedded projection is not realised in many languages (Cinque 2010). In (37), on may correspond only to a locational functional projection (PlaceP), or it may additionally realise (albeit covertly) the directional functional projection (PathP); this gives rise to its ambiguity. In the spirit of Kayne (2004), I assume that the directional functional projection is headed by the nonpronounced preposition TO, whose non-pronunciation is licensed by movement of overt material to a specifier (Kayne 2004; see also Koopman and Szabolcsi 2000, Collins 2007). The overt material is, in turn, licensed through (syntactic) adjacency with the verb, making available the interpretation Suarez ran TO on the pitch in (37a). Where that overt material is not licensed, it cannot move to the specifier, and a directional reading requires the overt preposition (It was onto $\left({ }^{*}\right.$ TO) the pitch that Suarez ran). ${ }^{20}$

\footnotetext{
${ }^{20}$ It is worth noting here that Liverpool p-drop is also distinct from the kind of p-drop found with nouns such as home in (presumably all varieties of) English, of the kind described in Collins (2007). It is well known that English exhibits obligatory and optional p-drop (depending on the syntactic environment) of to and at with a closed set of nouns: r-pronouns such as there, light nouns such as place or someplace, and (directional) home. Following Kishimoto (2000), Collins (2007) argues that these 'light' nominals obligatorily raise to the specifier of their embedding XP, locative TO/AT. Collins proposes that the raising of the light noun licenses the non-pronunciation of TO/AT, if something like Koopman and Szabolcsi's (2000:4) Generalised Doubly Filled Comp Filter holds, which states that no projection has both an overt specifier and an overt head at the end of a derivation.

As the examples throughout Section 4 show, p-drop in Liverpool English does not show a comparable sensitivity to nominal type. We could nonetheless extend Collins' analysis by stating that null TO/AT in Liverpool English triggers generalised movement of any nominal complement to SpecP. Leaving aside the question of what would trigger this generalised movement, a raising-to-spec analysis makes incorrect predictions with respect to word order. For example, following Collins, raising to Spec-P should mean that the nominal always precedes an adjective where a preposition is not overt. This analysis correctly predicts that both (1a) and (1c) should be fine, and (1b) excluded, in Standard English. However, (1b) is fine in Liverpool English. This suggests that raising-to-Spec is not the condition on nonpronunciation of the prepositions to and at in Liverpool English.
}

(1) a. They went someplace beautiful/mysterious.

b. They went some beautiful/mysterious place. (*Standard English/ ${ }^{\mathrm{OK}} \mathrm{L}$ 'pool English) 
All this is of significance because, although noting a preference for a non-directional reading in the cleft, Liverpool speakers volunteer that ambiguity also holds in the nonadjacent environment in (37b). Together, these facts point to the independence of the morphologically unmarked Goal from the verb in Liverpool English. If the unmarked Goal can occur in contexts non-adjacent to the predicate, the licensing of the Goal must be independent of the verb. I propose that the null element $\kappa$ itself licenses the Goal.

In sum the syntax of Liverpool preposition-drop is very different to that of prepositiondrop in the rest of the Northwest. In other varieties, p-drop is precisely restricted to those contexts in which the Goal is adjacent to the verb, consistent with an account where the Goal is licensed via p-incorporation (Myler 2013). All examples in this Section are ungrammatical in Ormskirk English (Myler 2013, Myler p.c.), as well as all the other Northwest dialects tested (see Section 2.2 for discussion). In contrast, in Liverpool English, $\kappa$ has the capacity to Case license independently of the verb.

Returning to the main topic of this paper, Sections 4.3 and 4.4 show precisely that it is variation in the adpositional functional lexicon that results in variation in the availability of Theme passivisation across Northwest varieties.

\subsection{The structure of $\kappa$}

If $\kappa$ licenses Case, we need to establish by what mechanism. I propose that Liverpool $\kappa$ corresponds to the functional head $p$, and that $\kappa(p)$ licenses Case on $\mathrm{NP}_{\text {Ground. }}$ (I label this

c. They went to some beautiful/mysterious place.

(Collins 2007: 11 (36), plus Liverpool judgement for (b))

(The availability of $\kappa$ does not exclude Collins' analysis of r-pronouns in the dialect. In fact I take there to be at least three types of 'p-drop' that can be distinguished in English, and that these can co-exist in a single grammar: non-pronunciation as a product of raising-to-spec (Kayne 2004, Collins 2007) for home; p-drop as p-incorporation (den Dikken 2010, Myler 2013); and the availability of null, purely functional adpositional elements, such as $\kappa$.) 
item $\kappa$ as in the literature; the role of $p$ is more usually identified as the introducer of the external argument of the adposition (Svenonius 2007, 2010), an issue that is not of direct concern here).

I propose that in Liverpool English, $\kappa(=p)$ lacks a $\theta$-selecting lexical complement. $\kappa$ is equivalent to a functional category $p$ that bears only $\mathrm{u}[\mathrm{F}]$, but lacks a 'lexical' head $\mathrm{P}$ (reminiscent of Collins' (2005) 'dummy prepositions', where a dummy preposition is a functional head that bears only $\mathrm{u}[\mathrm{F}]$; Collins' (2005) dummy preposition is the passive by 'ByP', where by is the head of VoiceP).

(38) $\kappa$ in Liverpool English

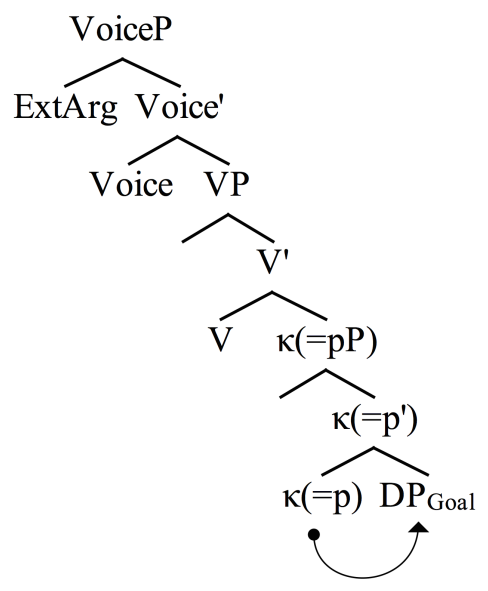

Following much previous work on adpositions, notably Rezac (2008), I assume that the $\mathrm{u}[\mathrm{F}]$ borne by adpositions are $\varphi$-features, and that Case is valued through Match and valuation of these features, as in standard Probe-Goal Agree (Chomsky 2000, 2001).

An alternative, that I will reject, is that $\kappa$ corresponds to a lexical head that both introduces an argument $\left(\mathrm{NP}_{\text {Ground }}\right)$ as its complement, and is responsible for Case licensing. As noted in the previous Section, much research on adpositions has shown that there must be multiple lexical projections internal to the extended projection of $\mathrm{P}$, which include $\mathrm{PathP}$ and PlaceP (Jackendoff 1990, Koopman 2010, Svenonius 2010, a.o). If th $\kappa$ corresponds to a 
lexical head, we expect there to be two null $\kappa$ heads in English, one relating to directionality ('dropped' to), and one to stativity ('dropped' at).

(39) $\kappa$ as the lexical projections PathP/PlaceP
a. $\kappa$ as $\mathrm{TO}_{\mathrm{Null}}$
b. $\kappa$ as $\mathrm{AT}_{\mathrm{Null}}$
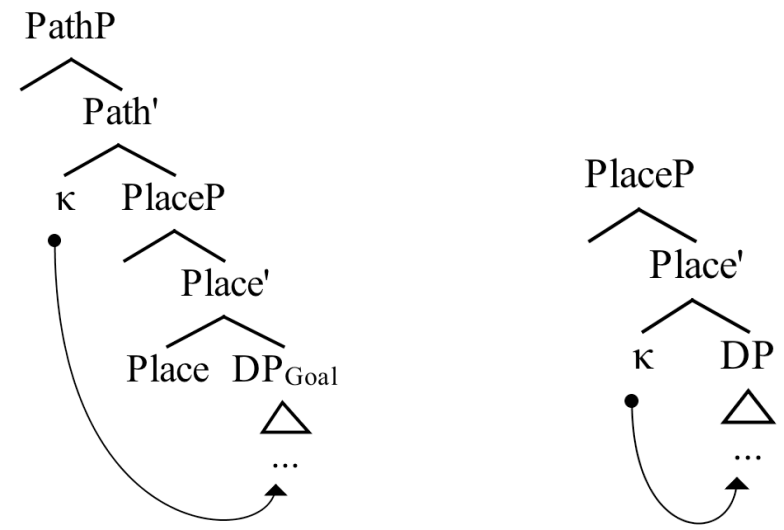

(39) is compatible with a traditional view of non-structural Case as thematic Case, such that the lexical head $\kappa$ assigns its complement Case as a consequence of thematic selection (Chomsky 1981, 1986). The former (38) is not (necessarily) compatible with this view of non-structural Case.

Close examination of the distribution of $\kappa$ suggests that Case licensing is the core function of $\kappa$ (consistent with (38)), and that $\kappa$ does not make a rich semantic contribution.

Pseudo-passives contribute initial evidence that Case licensing, rather that a semantic contribution, is the core role of $\kappa$ : Liverpool speakers do not permit $\kappa$ in pseudo-passives, instead requiring the overt preposition.

(40) a. John was talked *(to).

b. The music was listened *(to) carefully. 
c. After hours of discussion the contract was finally agreed $*($ to $){ }^{21}$

The syntactic structure of pseudo-passives, and especially their relation to their active counterparts, is controversial (see Hornstein and Weinberg (1981) and Baltin and Postal (1996) for discussion). The only point that is crucial here is that, as the object of the pseudopassive is probed and Case licensed by $\mathrm{T}$, the preposition of the pseudo-passive must not be a Case-licenser; the preposition still presumably supplies semantic information to the otherwise intransitive verb, however.

I propose that it this semantic contribution that means $\kappa$ is unavailable in the pseudopassive. ${ }^{22}$ As discussed for example (37): much previous work has shown that complex spatial concepts must be directly encoded in the internal structure of spatial adpositions Jackendoff 1990, Koopman 2000, Svenonius 2010). It has also been shown that overt lexical items may spell out different components of the articulated adpositional projection (Kayne 2004, Cinque 2010, Svenonius 2010), such that in some languages, or in some environments, complex semantic relations are overtly realised, and elsewhere they are not. For example, in

\footnotetext{
${ }^{21}$ As an anonymous reviewer points out, it is important to note here that Liverpool English does not otherwise allow agree as a transitive verb without a PP, as in 'They agreed it', an option apparently available in many American dialects.

${ }^{22}$ The same reviewer likens the pseudo-passive facts to Collins (2007) observation that $r$ pronouns (such as somewhere and nowhere) are ungrammatical in pseudo-passives:
}

(1) a. We drove (*to) somewhere interesting.

b. Nowhere interesting can be driven (*to) in under 5 minutes.

(Collins 2007: (15))

A null preposition cannot be stranded, if, as Collins argues, non-pronunciation is sensitive to a Doubly Filled Comp Filter (fn. 20): fronting the nominal in the pseudo-passive obviates the filter. In Liverpool English p-drop is available without raising-to-spec (fn. 20), so we take this to be a separate phenomenon.

On a related topic: it is difficult to assess whether a total ban on null p-stranding holds in the Liverpool grammar. For example, Liverpool English allows A-bar extraction from prepositional complements with a null preposition $(<$ Who $>$ did she give it? is fully acceptable), but in this environment is not clear whether the null preposition has simply undergone pied-piping. 
Italian the complex relation under might be taken to have the structure 'AT under (the sea)', as AT (in Italian, and, I think, marginally in English) can be realised in the environment of measure of phrases: Si trova (a) due metri sotto il livello del mare 'It is found (at) two meters under sea level' (Cinque 2010: 6).

I take the preposition in pseudo-passives such as (40) to be required to contribute a complex conceptual semantics; in the spirit of UNDER, I take the preposition in (40a) to have the structure, John was talked WITH to. Assume that $\kappa$ corresponds to $p$ without a lexical complement; without a lexical P complement, $\kappa$ cannot denote WITH; the semantic bleachedness of $\kappa$ then excludes it from the pseudo-passive. In contrast, an overt preposition has a lexical layer, and this layer may realise (potentially multiple) lexical layer(s) P. The restricted semantics of $\kappa / p$ means it is not freely interchangeable with any preposition, null or otherwise (cf. examples in (28); for discussion of the narrow semantic contribution of $\kappa$, see (ahead) fn. $24){ }^{23}$

In sum the unavailability of $\kappa$ in pseudo-passives follows (a) if the only function of $\kappa$ is to value Case, and (b) if $\kappa$ does not include a lexical $\mathrm{P}$ layer, such that it cannot denote complex spatial meanings.

The contrast between the overt $\mathrm{P}$ and $\kappa$ in terms of internal structure also gets us the distinction between the availability of $\kappa$ in prepositional datives and pseudo-passives: prepositional dative verbs subcategorise for - but do not Case license - the Goal argument; in

\footnotetext{
${ }^{23}$ We have already seen that $\kappa$ does not introduce a lexical $\mathrm{P}$ complement, it can optionally combine with a lexical P (for example, with on in the clefting example in (37)). As such we have to exclude its non-occurrence with a lexical P denoting null WITH. Following Kayne (2004) and Collins (2007), I assume that null WITH (and null PLACE, etc.) are not pronounced in English only as a result of movement of overt material to SpecP (fn. 20). Following Collins (2007), these null prepositions then cannot be stranded, excluding their availability in pseudo-passives, where the overt material is realised in SpecT (again, cf. fn. 20). $\kappa$ cannot combine with the null preposition, therefore, for the independent reason that the condition on the non-pronunciation of the null preposition WITH are not met. For partially related discussion of the unavailability of a null WITH in Northwest varieties more generally, see Myler (2013: 195).
} 
the pseudo-passive construction, $\mathrm{T}$ is responsible for Case licensing $\mathrm{NP}_{\text {Theme, }}$, but does not subcategorise for it, and nor does the intransitive pseudo-passive verb.

(41) a. I talked *(to) John.

b. I muttered the answer (to) John.

There is further evidence for the semantic bleachedness of $\kappa$, and its non-equivalence to the overt preposition, such that $\kappa$ represents a subset of the semantic functions associated with overt prepositions. For example, where at has a manner reading, $\kappa$ is ungrammatical:

(42) a. She was singing *(at) the top of her lungs.

b. She's moving *(at) a snail's pace.

$\kappa$ is also impossible wherever the complement of at has a more semantically complex reading than location.

(43) a. What are you getting *(at)?

b. He hit *(at) the wasp with a newspaper, but that only made it more angry.

c. Keep *(at) your job and some good luck might turn up...

d. I don't know when I'm going to get *(to) that paper.

If $\kappa$ were semantically equivalent to overt at, it should also be available in this environment. $^{24}$

\footnotetext{
${ }^{24} \mathrm{~A}$ reviewer questions how the interpretation of $\kappa$ can be constrained. I assume that as $\kappa$ is realised in the functional layer $p$, it necessarily denotes a spatial relation. (This would be comparable to the necessarily eventive interpretation of light verbs, or other functional
} 
Similarly: we have already seen that $\kappa$ is also available in contexts where the verb has an allative semantics. However, $\kappa$ is impossible where the complement is an idiom, or where $\mathrm{P}$ has a more 'complex' reading than allativity:

(44) a. You've got to pick a plan and stick*(to) it.

b. He looks up *(to) her.

If the distribution of $\kappa$ were to follow from itself supplying an allative-type $\theta$-role or selecting a strictly allative complement, its compatibility with ditransitive verbs such as donate, or manner of communication verbs such as whisper, yell, bark, grumble, mutter is unexpected. If, however, the ditransitive verb supplies the subcategorisation or selectional frame, highly plausible for ditransitive verbs, their compatibility with $\kappa$ is unsurprising.

projections in the vP shell, which are not otherwise associated with rich semantic content.) In the spirit of Kayne's (2004) analysis of PLACE vs. place, it is possible that the spatial interpretation of $\kappa$ is then restricted as a result of its featural paucity (featural paucity being a feature of functional items high in an extended projection; see Roberts and Roussou 2003 for discussion from a diachronic perspective). Assume that complex spatial concepts are directly encoded in the functional structure of adpositions (Koopman 2000, Svenonius 2010) and stipulate that DIRECTION (corresponding to a narrow subset of the interpretations of to) and LOCATION (corresponding to a narrow subset of the interpretations of $a t$ ) are associated with the least functional structure of any spatial concept (in the spirit of Jackendoff 1983). Concepts such as from are then excluded if they are structurally complex (contain a greater number of functional projections internal to the adpositional projection) relative to prepositions such as to; Pantcheva (2010) presents evidence that this may be the case. As $\kappa$ does not take a lexical P complement, it cannot denote these complex spatial meanings.

Similarly, I assume that interpretations of (overt) to or at 'richer' than DIRECTION/ LOCATION correspond to a rich functional structure not contained in $\kappa$. On this logic, without embedded functional structure, $\kappa$ can only be interpreted as DIRECTION/ LOCATION. Interpretation as DIRECTION/LOCATION then has to be recovered from elsewhere in the string, for example from the verb. (This is comparable to German examples like, Ich muss nach hause,: following van Riemsdijk (2002), this example contains a null featurally light motion verb $[\mathrm{e}]_{\mathrm{GO}}$. Relevant here is that it is only interpretable in the environment of (although not syntactically licensed by) a directional PP. 
Together the distributional data show that the syntactic object $\kappa$ can be formally distinguished from overt prepositions by the absence of thematic-related functional structure, such that it does not have a direct overt counterpart. This suggests we are not dealing with PFvariability.

Finally, this conclusion predicts an argument/ adjunct asymmetry with respect to $\kappa$. Adjuncts are not (usually) selected by the verb, and should therefore not be compatible with $\kappa$. In contrast, arguments of the verb are (usually) selected by the verb, and should therefore be compatible with $\kappa$. The following adjuncts are incompatible with $\kappa$, requiring an overt preposition:

(45) a. Let's meet*(at) six.

b. I'll find you *(at) last orders.

c. Sell it *(at) 180 .

d. I'm offering it (to) them *(at) cost.

Further argument/ adjunct asymmetries can be seen with the noun home. Home is one of the few English nouns with which (all varieties of) English permit (and sometimes require) a null preposition (cf. Collins 2007).

(46) a. I'll stay/go (*at/*to) home.

b. I'll be (at) home tonight.

The preposition is even obligatorily null with ditransitives (again for all speakers). This is true regardless of whether $\mathrm{NP}_{\text {Theme }}$ is inanimate or animate. 
(47) a. I'm sending this letter (*to) home.

b. I'm sending him (*to) home.

The only context in which a preposition is obligatorily overt with home nouns is in adjuncts.

(48) a. I'm cooking *(at) home tonight.

b. I'll work *(from) home tomorrow.

(Liverpool and Standard English)

Prepositions must likewise be overt in adjuncts in Liverpool English, indicating $\kappa$ is not compatible with adjuncts. ${ }^{25}$ This sensitivity holds both with the noun home (i.e. Liverpool judgements are consistent with the judgements given in (47) and (48)), as well as with nonhome nouns such as gym:

(49) a. She'll stay/go (at/to) the gym.

b. She'll be (at) the gym.

c. She's working out *(at) the gym tonight.

(Liverpool)

In short the restrictions on the distribution of $\kappa$ suggest that $\kappa$ is not itself introducing an argument, or assigning an argument a stative or allative theta-role. $\kappa$ is therefore a nonthematic Case licenser (functional head $p$ ), and not a thematic Case licenser (it does not contain a lexical head P).

${ }^{25}$ With some exceptions: examples such as Working (AT) the library (27b) are judged licit, for reasons that are not clear. 


\subsection{Consequences of the analysis}

If $\kappa$ has the same Case licensing capacity associated with overt prepositions, but without the capacity to $\theta$-license, the availability of Theme passivisation follows from the availability of $\kappa$ to Case license the Goal. There is plenty of evidence that this correlation holds true.

First, we have seen that the Liverpool dialect only drops the prepositions to and at. If TGDs (Theme-Goal ditransitives) and Theme passivisation are really Prepositional Datives with null $\kappa$, then TGDs and Prepositional Datives should not be possible with prepositions such as from (Source) or in (Containment), regardless of the lexical frame of the verb. As predicted, TGDs and Theme passivisation are unavailable with these preposition classes:

(50) a. Beth put the beers *(in) the cooler.

b. The beers were put *(in) the cooler.

(51) a. Beth exchanged notes *(with) Pete.

b. Notes were exchanged *(with) Pete.

(Liverpool)

In addition, as Liverpool English $\kappa$ is free wherever the verb provides an allative semantics (or stative semantics), TGDs and Theme passivisation should be available in any allative context. ${ }^{26}$ Evidence that this is the case comes from verbs-of-motion with inanimate

\footnotetext{
${ }^{26}$ An anonymous reviewer points out that Liverpool English should therefore be unlike Ormskirk English (as described in Myler 2013: 195) in allowing for p-drop with non-location goals with motion verbs. This prediction is partially borne out. In the following example, Ormskirk English does not permit p-drop. Liverpool English permits p-drop with the full DP but only allows the pronominal if the pronominal receives focal stress.
} 
or non-recipient Goals. In both 'standard' and Liverpool English, verbs-of-motion are incompatible with the DOC; the combination is possible only if the inanimate or non-recipient Goal is marked by the preposition to:

(52) a. I sent the letter to France.

b. *I sent France the letter.

If Liverpool TGDs are available in any context where to has a default allative interpretation, Liverpool TGDs should be possible with the inanimate Goal, regardless of the thematic properties of the Goal. The judgements from Liverpool speakers show that this prediction is correct:

(53) a. He sent the letter to France.

b. *He sent France the letter.

c. He sent the letter France.

(54) a. Betty sent Joe to the pub.

b. *Betty sent the pub Joe.

c. Betty sent Joe the pub.

(Liverpool)

(1) He came (to) me / the man for help. *Ormskirk; ${ }^{\text {OK/?? Liverpool }}$ (Myler 2013: 195)

I have not explored the interplay between stress and p-drop or TGDs, but such an investigation could be very revealing (especially given a second anonymous reviewer's judgments; see fn. 27). 
This is predicted if Liverpool TGDs are underlying Prepositional Datives with a null preposition.

Finally, Theme passivisation is also available with inanimate Goals of verbs-of-motion and with non-recipient Goals (55a, 56a). $(55 \mathrm{~b}, 56 \mathrm{~b})$ demonstrate that as in 'standard' varieties of English, Goal passivisation is not possible in this context:

(55) a. The letter was sent France.

b. *France was sent the letter.

(56) a. John was sent the pub.

b. *The pub was sent John.

In contrast to Liverpool English, Manchester English does not accept inanimate Goals with verbs of motion, either in TGDs or in Theme passives.

(57) a. I sent the letter to France.

b. *I sent France the letter.

c. *I sent the letter France.

(Manchester, Haddican 2010: 2430; Ormskirk, Myler p.c.)

(58) It was sent France.

(*Manchester,

*Ormskirk)

These latter contrasts follow if the Manchester TGD and Theme passive derive from a distinct underlying syntactic structure, namely the DOC, rather than the Prepositional Dative. 
The availability of the null preposition in the dative alternation may have broader implications for work on the underlying structure of the dative alternation in English. There has been much debate over whether either the prepositional dative or the Double Object Construction is transformationally related to the other (cf. Oehrle 1976, Larson 1988, Hallman 2015 i.a.). Although both transformational and non-transformational (e.g. Harley 2002) accounts of the dative alternation posit null prepositions, there has been relatively little discussion of morphosyntactic composition of the null preposition. The present study indicates that this null preposition should be of central concern in defining the representation of ditransitives. In particular, the distribution of the Liverpool null preposition in the dative alternation (e.g. (53b), (54b)) represents evidence against the transformational account where a double object construction derives from the prepositional dative, with non-pronunciation of the preposition (Larson 1988). Instead, the restriction of the null preposition to the prepositional dative indirectly supports an analysis where the prepositional dative and double object construction have distinct underlying structures.

\section{The systematic nature of regional variation: evidence from Manchester English}

Haddican (2010) and Haddican and Holmberg (2012) present convincing evidence that TGDs derive from a DOC in the Northwest, with the direct object $\left(\mathrm{NP}_{\text {Theme }}\right)$ undergoing local object movement to form the TGD.

(59) a. It was given her.

b. I gave it her (it).
Theme passive

$T G D / D O C$
( ${ }^{\mathrm{OK}}$ Manchester, ${ }^{\mathrm{OK}}$ Ormskirk)

( ${ }^{\mathrm{OK}}$ Manchester, ${ }^{\mathrm{OK}}$ Ormskirk) 
First, Manchester English speakers (and speakers of the other Northwest varieties) reject TGDs with verbs of continuous imparting force, manner of communication verbs, and latinate verbs:

(60) a. She pushed/hauled/lifted it to me.

PD

b. *She pushed/hauled/lifted me it.

DOC

c. *She pushed/hauled/lifted it me.

TGD

(61) a. She whispered/shouted it to me.

PD

b. *She whispered/shouted me it.

DOC

c. *She whispered/shouted it me.

TGD

(62) a. She donated/contributed it to me.

PD

b. * She donated/contributed me it.

DOC

c. *She donated/contributed it me.

TGD

(Manchester, Haddican 2010: 2428; Ormskirk, Myler p.c.; Southport, own investigation)

Second, Manchester English speakers (and speakers of the other Northwest varieties) accept TGDs with verbs of prevention of possession (such as refuse, deny):

(63) a. *She refused it to me.

PD

b. She refused me it.

DOC

c. \%She refused it me.

TGD

(Manchester, Haddican 2010: 2428; own fieldwork) 
This suggests that in the Northwest speakers treat TGDs as if they were DOCs. If there is a correlation between the availability of Theme passivisation and TGDs, only those verb classes compatible with TGDs should be compatible with Theme passivisation. This prediction is borne out: verbs of prevention of possession are compatible with Theme passivisation in Manchester English, but verbs of continuous imparting force, manner of communication verbs, or latinate verbs are not (a-c). I found that the former class is only marginally acceptable (d), but the trend is nonetheless clear.

(64) a. *It was pushed me.

b. *It was shouted me.

c. *It was donated me.

d. ? It was denied her.

('Northwest' varieties)

In contrast to 'standard' varieties of English, then, speakers of Northwest varieties permit the Theme pronominal to undergo local object movement in a DOC (Haddican and Holmberg 2012).

Following Haddican \& Holmberg (2012), I take speakers of dialects that permit TGDs and theme passivisation derived from DOCs to have innovated a LinkerP (in the sense of Baker and Collins 2006) that can merge between Voice and $v^{2}$ in DOCs, where $v^{2}$ is the applicative-like head proposed in Adger and Harbour (2007). LkP merges bearing uninterpretable $[\varphi]$, such that a relation with it results in (structural) Case valuation. Crucially, still following Haddican \& Holmberg (2012), [ $\varphi$ ] may be merged with either LkP or $v^{2}$.

(65) Manchester Double Object Constructions/ Theme-Goal Ditransitives 


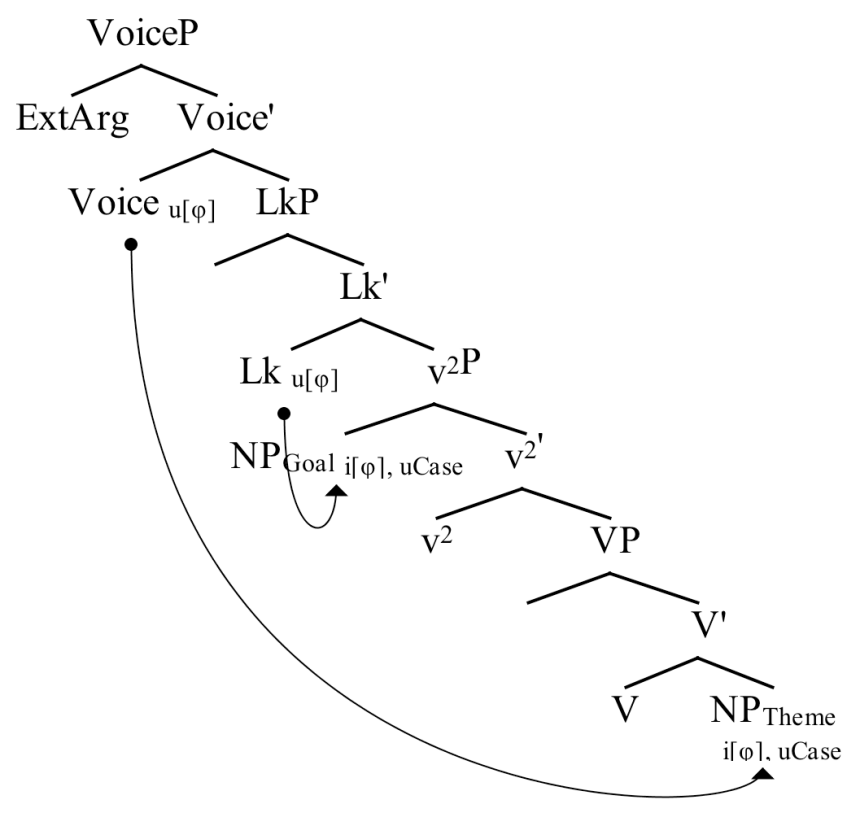

LkP Probes for its most local Goal, which, here, is the Goal argument in Appl. Under Agree, LkP values the $u$ [Case] on the Goal. This 'deactivation' of the Goal means it is no longer a possible intervener for Agree (Baker 1988, Chomsky 2001 i.a.). Where LkP values the features of the Goal, the Theme is the most local argument to Voice. $u[\varphi]$ on Voice thus probes the Theme, with which it Agrees under Match.

It is the Agree relation between $v$ and the pronominal Theme that results in the Theme $>$ Goal word order. However, the relationship between little $v$ and the Theme is somewhat restricted. As noted in Section 2, TGDs in Manchester English are mostly restricted to pronominal themes:

(66) a. She gave it him.

$$
\begin{aligned}
& \text { pro }>\text { pro } \\
& \text { pro }>\text { DP } \\
& \text { DP }>\text { pro }^{27}
\end{aligned}
$$

b. She gave it the boy

c. ${ }^{(?)}$ She gave the ball him.

\footnotetext{
${ }^{27}$ An anonymous reviewer with DOC-type TGDs finds example (c) acceptable with focal stress on the pronominal. It is possible that this type of stress is also required of Manchester
} 

d. ${ }^{(? ? / *)}$ She gave the ball the boy.
$\mathrm{DP}>\mathrm{DP}$

(Haddican 2010: 2426)

Agree in the derivation in (65) above therefore entails that $\mathrm{NP}_{\text {Theme }}$ is licensed, but not that it 'moves'. Haddican \& Holmberg (2012) propose that pronominal Theme 'movement' in TGDs is actually incorporation, in the sense of Roberts (2010a).

Roberts' system takes as its starting point the familiar Agree relation, where features are copied onto the categories that Agree. Roberts (2010a) proposes that where an element $\alpha$ contains a proper subset of the features of a second element $\beta$, and $\alpha$ enters an Agree relation with $\beta$, the element $\alpha$ is a 'defective' goal. Roberts (2010a: 66) proposes that when a defective goal enters an Agree relation, copying the features of the goal exhausts the contents of the goal. Just as in Chain Reduction where all identical copies of a chain are deleted leaving only the highest (Nunes 2004), a defective goal will be realised in the structural position of its probe, and the goal itself 'deletes'. It is the realisation of the goal in the Probe's structural position that yields the appearance of incorporation.

For Roberts (2010b) and Haddican \& Holmberg (2012), pronouns are $\varphi$ Ps. In Roberts' (2010a) terms, then, pronouns ( $\varphi \mathrm{Ps})$ are proper subsets of the $u[\mathrm{~F}]$ on little $v$, as little $v$ also contains features such as the category and the thematic information of the external argument. In the context of a pronoun (a $\varphi \mathrm{P})$ undergoing valuation by Voice, all feature values of the $\varphi \mathrm{P}$ are represented on the Probe Voice; as such, the $\varphi \mathrm{P}$ is essentially a copy of the Probe, and thus, for Roberts (2010a), may 'incorporate' to Voice. Chain Reduction, as above, yields the overt ordering of the Theme preceding the Goal (a TGD).

speakers, but this was not tested in survey carried out here. Interestingly, the same reviewer finds (d) acceptable. As this grammar is not captured by Haddican and Holmberg's (2012) incorporation analysis, variation is even more extensive than that reported here. I leave both issues to future investigation. 
Incorporation results in the nominal/ pronominal asymmetry in both TGDs and Theme passives. Under 'incorporation', only an XP bearing a subset of the features of the Probe is a potential Goal. It is for this reason that pronominal Themes $(\varphi \mathrm{Ps})$, but not definite Themes (DPs), occur as TGDs in this dialect: Voice may probe a DP Theme, but as DP does not constitute a subset of the features on Voice, the familiar DOC order is realized. It then follows that only incorporated $\varphi$ Ps (pronominals) are sufficiently local to $\mathrm{T}$ to occur in the Theme passive.

There are still further dialects (noted in Haddican and Holmberg 2012, and which an anonymous reviewer speaks) that permit DP TGDs, but not DP Theme passives. There may be an additional locus of variation that restricts the availability of Theme passives; I leave this to future investigation. In the Manchester dialect, the availability of short object movement in TGDs can be taken to follow from the distribution of $\varphi$-features across Voice, LkP, and $v^{2}$.

\section{The locus of parametric variation}

In Section 3 I proposed that in the Liverpool dialect, apparent Theme passives derive from Prepositional Datives and in Section 4 I hypothesised that the possibility of an absent preposition in the Prepositional Dative in the Liverpool variety is the result of an innovated null element ' $\kappa$ '; I argued that $\kappa$ has the same Case licensing capacity associated with overt prepositions, but without the capacity to $\theta$-mark.

In Section 5, following Haddican (2010) and Haddican and Holmberg (2012), Manchester English was shown to contrast with the neighboring Liverpool English dialect in deriving the active Theme-Goal order (and consequent Theme passive) via short object movement. 
Section 2 introduced the question of the locus of parameters in the grammatical architecture. It is usual to assume that the syntax (for example, Agree and Merge) is uniform, and that syntactic variation instead reflects variation in the inventory of syntactic features and their distribution across functional heads (Baker's (2008) Borer-Chomsky Conjecture). The analysis of short object movement in Section 5, taken to follow from the distribution of $\varphi$ features across a range of vP-internal projections, is clearly an example of such morphosyntactic variation.

An alternative position is that all variation is PF-variation (Berwick and Chomsky 2008). Preposition-drop in Liverpool English might seem a highly plausible example of PFvariability, where, for example, $\kappa$ might actually be the elided or non-phonetically realised versions of to or at. However, the data in Section 4 (especially Section 4.3) demonstrate that the 'dropped preposition' $\kappa$ is not (morpho-)syntactically equivalent to the overt prepositions to and at. The non-equivalency of $\kappa$ to the overt prepositions to and at represents strong evidence against an analysis of preposition-drop as an example of PF-variability. (The conclusion that 'dropped' prepositions are non-equivalent to their overt counterparts is also reached in work on preposition-drop in other varieties (Kayne 2005; Collins 2007; Ioannidou and den Dikken 2009; Terzi 2010; Myler 2011, 2013)). Instead, the sensitivity of $\kappa$ to such a broad array of semantic and syntactic environments indicates it bears a distinct functional structure, and that $\kappa$ is a morpho-syntactically distinct lexical item. Variation between the Liverpool and Manchester dialects thus follows from the distribution of features across specific functional heads.

This variation in the functional lexicon (variation in the distribution of a set of features on functional heads) acts parametrically, in the sense that it results in a range of syntactic properties traceable to a single point of variation. In particular we have shown that the parametric variation captures the systematic syntactic restrictions on theme passivisation that 
differ across the region, including (a) the class of the ditransitive verb that can participate in theme passives (prepositional dative vs. double object construction dative) (b) restrictions on the compatibility of certain goal arguments with theme passivisation (goals marked by in; inanimate goals), and (c) the type of theme argument that may undergo passivisation (pronominal vs. nominal); these properties do not follow if variation is located in a postsyntactic domain.

\section{Conclusion}

This paper has examined the availability of theme passivisation in apparent Double Object Constructions in Manchester and Liverpool English.

Section 3 showed, however, that in the Liverpool dialect, Theme passives derive from Prepositional Datives, resulting in the following regional differences:

Table 1

\begin{tabular}{|c|c|c|c|}
\hline & Full DP Theme & Prepositional Dative & Inanimate Goal \\
\hline Liverpool & $\boldsymbol{J}$ & $\boldsymbol{X}$ & $\checkmark$ \\
\hline Manchester & $\boldsymbol{X}$ & $\boldsymbol{X}$ & $\boldsymbol{X}$ \\
\hline
\end{tabular}

Section 4 hypothesised that the possibility of an absent preposition in the Prepositional Dative in the Liverpool dialect is the result of an innovated null element $\kappa . \kappa$ corresponds to a functional head $p$ and licenses Case on $\mathrm{NP}_{\text {Goal }}$. I suggested the availability of $\kappa$ in ditransitives extends from the increasing availability of p-drop in Liverpool English, where p-drop is available in a much wider range of contexts than is found elsewhere in the Northwest, and specifically Ormskirk English (as described in Myler 2013). Table 2 summarises some of the differences.

\section{Table 2}




\begin{tabular}{|c|c|c|c|}
\hline p-drop available: & Directed motion & Location & $\begin{array}{c}\text { Nominal non- } \\
\text { adjacent to V }\end{array}$ \\
\hline Liverpool & $\checkmark$ & $\checkmark$ & $\checkmark$ \\
\hline Ormskirk & $\checkmark$ & $\boldsymbol{X}$ & $\boldsymbol{X}$ \\
\hline
\end{tabular}

A novel aspect of the analysis is that $\kappa(=p)$ lacks a lexical complement, i.e. $p$ does not embed PP: $\kappa$ has the same Case licensing capacity associated with overt prepositions, but without the capacity to $\theta$-select. Preposition-drop in Liverpool English, and its interaction with ditransitive verbs and consequently theme passivisation, therefore constitutes evidence for the possibility of fully dissociating formal licensing from $\theta$-selection in environments canonically taken to involve 'inherent' Case (Biggs 2014). Such a structure also has the implication that functional projections, here functional $p$, may be available independent of the 'lexical' component (e.g. P); this can be seen as an extension of the familiar claim from work on the verbal domain on the availability of 'light verbs', such that the structure of prepositions mirrors that of verbs (Svenonius 2007).

In contrast, following Haddican (2010), I have assumed that theme passivisation in Manchester English derives from an underlying Double Object Construction. As in Haddican and Holmberg (2012) this is taken to follow from variation in the distribution of $\varphi$-features across vP-internal functional heads.

Detailed investigation of apparently variable syntax therefore suggests that in both dialects syntactic variation is best represented at the level of the functional lexicon. 


\section{References}

Aboh, Enoch. 2010. The P route. In Guglielmo Cinque and Luigi Rizzi (eds.), Mapping spatial PPs, 225-260. Oxford: Oxford University Press.

Adger, David. 2006. Combinatorial variability. Journal of Linguistics 42:503-530.

Adger, David and Daniel Harbour. 2007. Syntax and syncretisms of the Person Case Constraint. Syntax 10.1: 2-37.

Adger, David and Jennifer Smith. 2010. Variation in agreement: A lexical feature-based approach. Lingua 120: 1109-1134

Anagnostopoulou, Elena. 2003. The syntax of ditransitives: evidence from clitics. Berlin: Mouton de Gruyter.

Baltin, Mark and Paul M. Postal. 1996. More on reanalysis hypotheses. Linguistic Inquiry 27.1: 127-145.

Baker, Mark. 2008. The Macroparameter in a Microparametric World. In Theresa Biberauer (ed.), The Limits of Syntactic Variation, 351-374. Amsterdam: John Benjamins.

Barbiers, Sjef (Ed.). 2008. Microvariation in Syntactic Doubling. Bingley: Emerald.

Berwick, Robert, and Noam Chomsky. 2008. 'Poverty of the stimulus' revisited: Recent challenges reconsidered. Proceedings of the 30th annual conference of the cognitive science society.

Biberauer, Theresa, Ian Roberts and Michelle Sheehan. 2014. No-choice parameters and the limits of syntactic variation. In R. Santan-LaBarge (ed.), Proceedings of WCCFL 31. Somerville, MA: Cascadilla Press.

Biggs, Alison. 2014. Dissociating Case from theta-roles. PhD dissertation, University of Cambridge. 
Borer, Hagit. 1984. Parametric Syntax. Foris, Dordrecht.

Bresnan, Joan and Marilyn Ford. 2010. Predicting syntax: Processing dative constructions in American and Australian varieties of English. Language 86.1: 168-213.

Bresnan, Joan and Tatiana Nikitina. 2009. The Gradience of the Dative Alternation. In Linda Uyechi and Lian Hee Wee (eds.) Reality Exploration and Discovery: Pattern Interaction in Language and Life, 161-184. Stanford: CSLI Publications

Caponigro, Ivano and Lisa Pearl. 2008. Silent prepositions: evidence from free relatives. In Anna Asbury, Jakub Dotlacil, Berit Gehrke, and Rick Nouwen (eds.) The Syntax and Semantics of Spatial P, 365-385. Amsterdam: Benjamins.

Chomsky, Noam. 1981. Lectures on government and binding. Dordrecht: Foris.

Chomsky, Noam. 1986. Knowledge of Language: its Nature, Origin and Use. New York: Praeger.

Chomsky, Noam. 1995. The minimalist program. Cambridge, MA: MIT press.

Chomsky, Noam. 2000. Minimalist inquiries: The framework. In Roger Martin, David Michaels, Juan Uriagereka and Samuel Jay Keyser (eds.), Step by step: Essays on Minimalist syntax in honor of Howard Lasnik, 89-156. Cambridge, MA: MIT Press.

Chomsky, Noam. 2001. Derivation by phase. In Michael Kenstowicz (ed.), Ken Hale: A life in language, 1-52. Cambridge, MA: MIT Press.

Collins, Chris. 2005. A smuggling approach to the passive in English. Syntax 8: 81-120.

Collins, Chris. 2007. Home Sweet Home. NYU Working Papers in Linguistics 1: 1-27.

Cornips, Leonie and Karen Corrigan (eds). 2005. Syntax and variation: reconciling the biological and the social. Amsterdam: John Benjamins Publishing.

den Dikken, Marcel. 1995. Particles: On the syntax of verb-particle, triadic and causative constructions. Oxford: Oxford University Press.

Emonds, Joseph. 1985. A unified theory of syntactic categories. Dordrect: Foris. 
Gehrke, Berit and Marika Lekakou 2013. How to miss your preposition. Studies in Greek Linguistics 33: 92-106.

Gerwin, Joanna. 2013. Give it me!: pronominal ditransitives in English dialects. English Language and Linguistics 17.3: 445-463.

Gerwin, Joanna. 2014 Ditransitives in British English Dialects. Berlin: Walter de Gruyter.

Green, Georgia. 1974. Semantics and Syntax Regularity. Bloomington, IN: Indiana University Press.

Haddican, William. 2010. Theme-goal ditransitives and theme passivisation in British English dialects. Lingua 120: 2424-2443.

Haddican, William and Anders Holmberg. 2012. Object movement symmetries in British English dialects: Experimental evidence for a mixed case/locality approach. The Journal of Comparative Germanic Linguistics 15.3: 189-212.

Hallman, Peter. 2015. Syntactic Neutralization in Double Object Constructions. Linguistic Inquiry 46: 389-424.

Harley, Heidi. 2002. Possession and the double object construction. Linguistic Variation Yearbook 2: 31-70.

Holmberg, Anders. 2010. Null subject parameters. In Theresa Biberauer, Anders Holmberg, Ian Roberts, and Michelle Sheehan (eds.), Parametric variation: Null subjects in minimalist theory, 88-124. Cambridge: Cambridge University Press.

Hornstein, Norbert and Amy Weinberg. 1981. Case theory and preposition stranding. Linguistic Inquiry 12: 55-91.

Hughes, Arthur and Peter Trudgill. 1979. English accents and dialects: an introduction to social and regional varieties of British English. London: Edward Arnold. 
Ioannidou, Alexandra and Marcel den Dikken. 2009. P-drop, D-drop, D-spread. In Claire Halpert, Jeremy Hartman, and David Hill (eds.) Proceedings of the 2007 Workshop in Greek syntax and semantics at MIT, 393-408. Cambridge, MA: MITWPL.

Jackendoff, Ray. 1973. The Base Rules for prepositional phrases. In S. Anderson and Paul Kiparsky (eds.) A festschrift for Morris Halle, 345-66. New York: Holt, Rinehart, and Winston.

Jackendoff, Ray. 1983. Semantics and Cognition. Cambridge, MA: MIT Press.

Jackendoff, Ray. 1990. Semantic structures. Cambridge, MA: MIT Press.

Jeong, Youngmi. 2007. Applicatives: Structure and interpretation from a minimalist perspective. Amsterdam: John Benjamins.

Kayne, Richard S. 2004. Here and There. In C. Leclère et al. (eds.), Lexique Syntaxe, et Lexique-Grammaire/Syntax, Lexis and Lexicon Grammar: Papers in Honour of Maurice Gross, 253-275. Amsterdam: John Benjamins.

Kayne, Richard S. 2005. Kayne, Richard S. Some notes on comparative syntax, with special reference to English and French. In Guglielmo Cinque and Richard Kayne (Eds.), The Oxford handbook of comparative syntax, 3-69. Oxford: Oxford University Press.

Koopman, Hilda. 2000/2010. Prepositions, Postpositions, Circumpositions, and Particles. In Guglielmo Cinque and Luigi Rizzi (eds.) Mapping spatial PPs, 26-73. Oxford: Oxford University Press.

Koopman, Hilda and Anna Szabolcsi. 2000. Verbal Complexes. Cambridge: MIT Press.

Larson, Richard K. 1988. On the Double Object Construction. Linguistic Inquiry 19.3: 335391.

Levin, Beth. 1993. English verb classes and alternations. Cambridge, MA: MIT Press.

Marantz, Alec. 2001. Words. In 20th West Coast Conference on Formal Linguistics, University of Southern California, 23-25. 
McGinnis, Martha. 1998. Locality in A-movement. PhD dissertation, MIT.

McGinnis, Martha. 2001. Variation in the phase structure of applicatives. Linguistic Variation Yearbook 1: 105-146.

Myler, Neil. 2011. Come the pub with me: silent TO in a dialect of British English. NYU Working Papers in Linguistics 3: 120-135.

Myler, Neil. 2013. On coming the pub in the North West of England: accusative unaccusatives, dependent case and preposition incorporation. The Journal of Comparative Germanic Linguistics 16.2-3: 189-207.

Nunes, Jairo. 2004. Linearization of chains and sideward movement. Cambridge, MA: MIT Press.

Oehrle, Richard T. 1976. The Grammatical Status of the English Dative Alternation. PhD Dissertation, MIT.

Pantcheva, M. (2010). The syntactic structure of locations, goals, and sources. Linguistics 48.5: 1043-1081.

Pesetsky, David. 1995. Zero Syntax. Cambridge, MA: MIT Press.

Pinker, Steven. 1989. Learnability and cognition: the acquisition of argument structure. Cambridge, MA: MIT Press.

Pylkkänen, Liina. [2002] 2008. Introducing arguments. Cambridge, MA: MIT Press.

Rezac, Milan. 2008. $\varphi$-Agree and Theta-related Case. In Daniel Harbour, David Adger, and Susana Béjar (eds.) $\varphi$ theory: $\varphi$-features across interfaces and modules. Oxford: Oxford University Press.

van Riemsdijk, Henk. 2002. The unbearable lightness of GOing. Journal of Comparative Germanic Linguistics 5: 143-196.

Roberts, Ian. 2010a. Agreement and head movement: Clitics, incorporation and defective goals. Cambridge, MA: MIT Press. 
Roberts, Ian. 2010b. A deletion analysis of null subjects. In Theresa Biberauer, Anders Holmberg, Ian Roberts, and Michelle Sheehan (eds.), Parametric variation: Null subjects in minimalist theory, 58-87. Cambridge: Cambridge University Press.

Roberts, Ian and Anders Holmberg. 2010. Introduction: Parameters in minimalist theory. In Theresa Biberauer, Anders Holmberg, Ian Roberts, and Michelle Sheehan (eds.) Parametric variation: Null subjects in minimalist theory, 1-57. Cambridge: Cambridge University Press.

Roberts, Ian and Anna Roussou. 2003. Syntactic change: A minimalist approach to grammaticalization. Cambridge: Cambridge University Press.

Siewierska, Anna and Willem Hollmann. 2007. Ditransitive clauses in English with special reference to Lancashire dialect. In Mike Hannay and Gerard J. Steen (eds.) Structuralfunctional studies in English grammar: in honour of Lachlan Mackenzie, 83-102. Amsterdam: Benjamins.

Svenonius, Peter. 2007. Adpositions, particles, and the arguments they introduce. In Eric Reuland, Tanmoy Bhattacharya, and Giorgos Spathas (eds.) Argument Structure, 71110. Amsterdam: John Benjamins.

Svenonius, Peter. 2010. Spatial prepositions in English. In Guglielmo Cinque and Luigi Rizzi (eds.) Mapping spatial PPs, 127-160. Oxford: Oxford University Press.

Terzi, Arhonto. 2010. Locative prepositions and Place. In Guglielmo Cinque and Luigi Rizzi (eds.) Mapping spatial PPs, 196-224. Oxford: Oxford University Press.

Torrego, Esther. 1998. The dependencies of objects. Cambridge, MA: MIT Press.

Ura, Hiroyuki. 2000. Checking theory and grammatical functions in Universal Grammar. Oxford: Oxford University Press.

Wolfram, Walt and Natalie Schilling-Estes. 2006. American English, 2nd Edition. Oxford: Blackwell. 
Woolford, Ellen. 1993. Symmetric and asymmetric passives. Natural Language and Linguistic Theory 11.4: 679-728.

Zanuttini, Raffaella and Laurence Horn, (eds). 2014. Micro-syntactic Variation in North American English. Oxford: Oxford University Press. 